\title{
Pleural Effusion with Mediastinal and Hemidiaphragm Mass Effect: A Case Report
}

\author{
Rachel E. Bridwell ${ }^{1}$, Michael J. Yoo ${ }^{1}$, Joshua J. Oliver ${ }^{2}$ \\ 1. Emergency Medicine, Brooke Army Medical Center, Fort Sam Houston, USA 2. Emergency Medicine, San Antonio \\ Uniformed Services Health Education Consortium, Fort Sam Houston, USA
}

Corresponding author: Rachel E. Bridwell, r.e.bridwell@gmail.com

\begin{abstract}
Pulmonary metastases are a rare but aggressive and life-threatening complication of leiomyosarcoma. We discuss a case of a 48 -year-old woman with stage $4 \mathrm{~b}$ leiomyosarcoma who presented with dyspnea and hemodynamic instability secondary to a large lung metastasis with massive pleural effusion. This particular subset of patients is vulnerable to re-expansion pulmonary edema in a disease with poor survival rates.
\end{abstract}

Categories: Emergency Medicine, Oncology, Pulmonology

Keywords: pulmonary effusion, leiomyosarcoma, metastases

\section{Introduction}

Leiomyosarcomas are rare but aggressive soft tissue tumors associated with a poor prognosis and affecting approximately 0.36 per 100,000 women-years [1]. These tumors typically present with abnormal uterine bleeding and early metastases to the lung. There is one pulmonary leiomyosarcoma per 3000 pulmonary carcinomas reported [2]. However, minimal case studies document significant cardiopulmonary complications secondary to pulmonary metastases and subsequent cardiovascular compromise. We discuss a 48-year-old woman with a history of metastatic leiomyosarcoma who presented to the emergency department with acute dyspnea, hemoptysis, and hypotension and was found to have a large left-sided pleural effusion causing mediastinal, hemidiaphragmatic, renal, and splenic shift.

\section{Case Presentation}

A 48-year-old woman with a history of stage $4 \mathrm{~b}$ leiomyosarcoma with lung metastases diagnosed in 2016 status post-hysterectomy and on active doxorubicin and dacarbazine presented to the emergency department (ED) with acute shortness of breath and scant hemoptysis. On a further review of systems, the patient endorsed dyspnea on exertion that improved with rest and upright position, orthopnea, paroxysmal nocturnal dyspnea, and subjective fevers. She denied chest pain, diaphoresis, or chills. Further history and chart review revealed known lung metastases to include: an $8.9 \times 8.5 \times 6.3 \mathrm{~cm}$ posterior left lower lobe complex mass, $1.3 \mathrm{~cm}$ left upper lobe solid nodule, and a $6 \mathrm{~mm}$ right upper lobe subpleural pulmonary nodule. These findings were identified on computed tomography (CT) of the chest performed three weeks prior to presentation. The patient had been in her baseline state of health prior to this ED visit and underwent her scheduled doxorubicin and dacarbazine infusion two days prior.

On arrival, the patient's vital signs included: heart rate of 133 beats per minute (bpm), blood pressure of $69 / 50 \mathrm{mmHg}$, temperature of $101.1^{\circ} \mathrm{Fahrenheit}$, and pulse oximetry of $95 \%$ on room air. The patient's physical exam was remarkable for conjunctival pallor, decreased breath sounds, and dullness to percussion on the patient's right posterior lung fields. Intravenous access was established, and the patient received one unit of fresh whole blood followed by 2 liters of lactated Ringer's solution and 1 gram of cefepime. The patient's blood pressure and heart rate improved to $110 / 60 \mathrm{mmHg}$ and $110 \mathrm{bpm}$, respectively. A subsequent contrasted CT of the chest, abdomen, and pelvis demonstrated a large left pleural effusion causing a nearly complete collapse of the left upper and lower lung. Mass effect was also noted, to include a rightwards mediastinal shift and a downwards left hemidiaphragm shift displacing the spleen and left kidney inferiorly (Figures 1-2). Serum studies revealed 350 white blood cells per $\mathrm{mm}$ of blood, 35 neutrophils per $\mathrm{mm}$ of blood, and a platelet count of 17,000 . The patient was administered six units of platelets and admitted to the medical intensive care unit (MICU) where 2 liters of sanguineous pleural fluid were drained with thoracentesis. 


\section{Cureus}

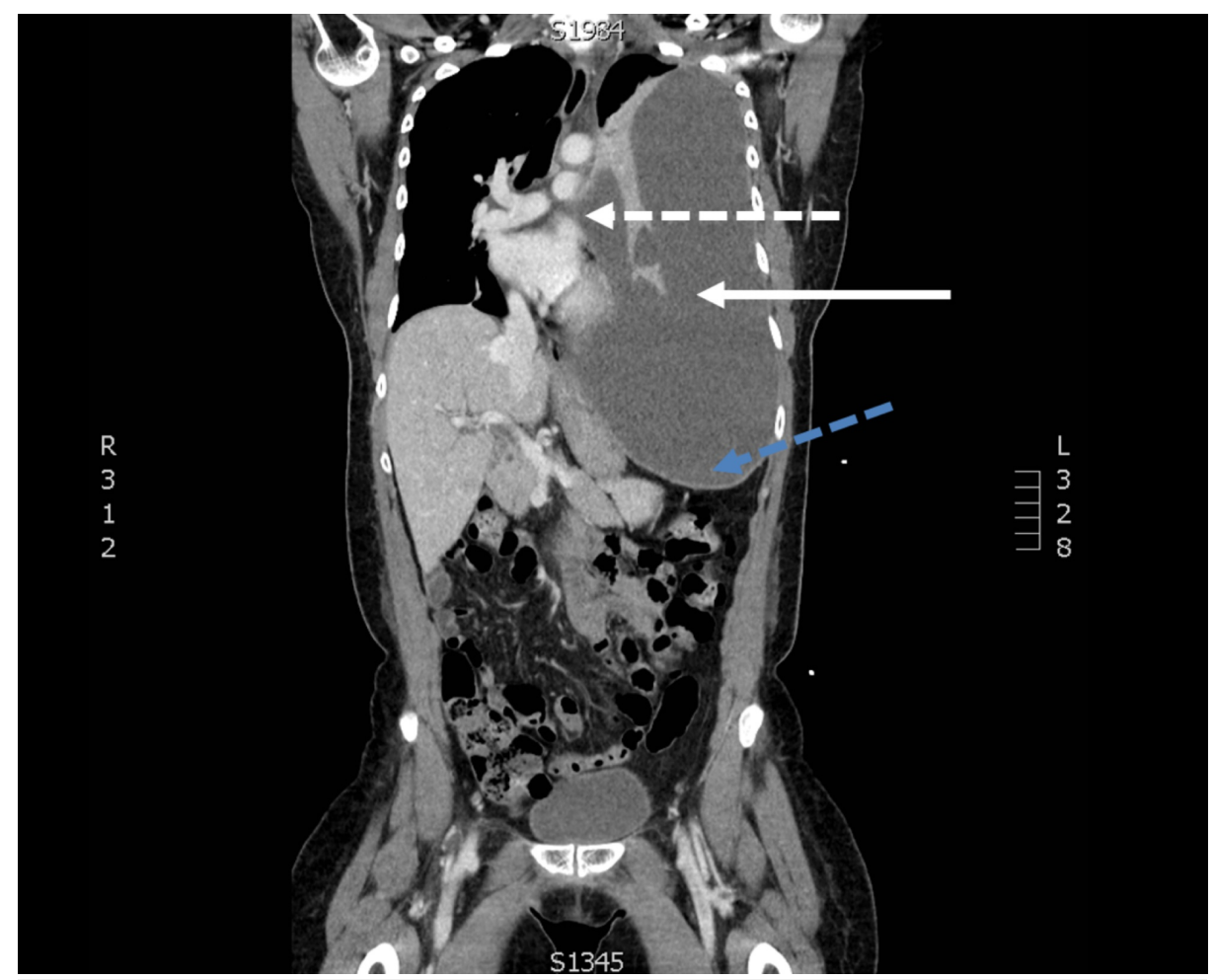

FIGURE 1: A coronal slice of a contrasted computed tomography of the chest, abdomen, and pelvis demonstrating a large left-sided pleural effusion (solid white line) with mass effect on the mediastinum (dashed white line) and left hemidiaphragm (dashed blue line)

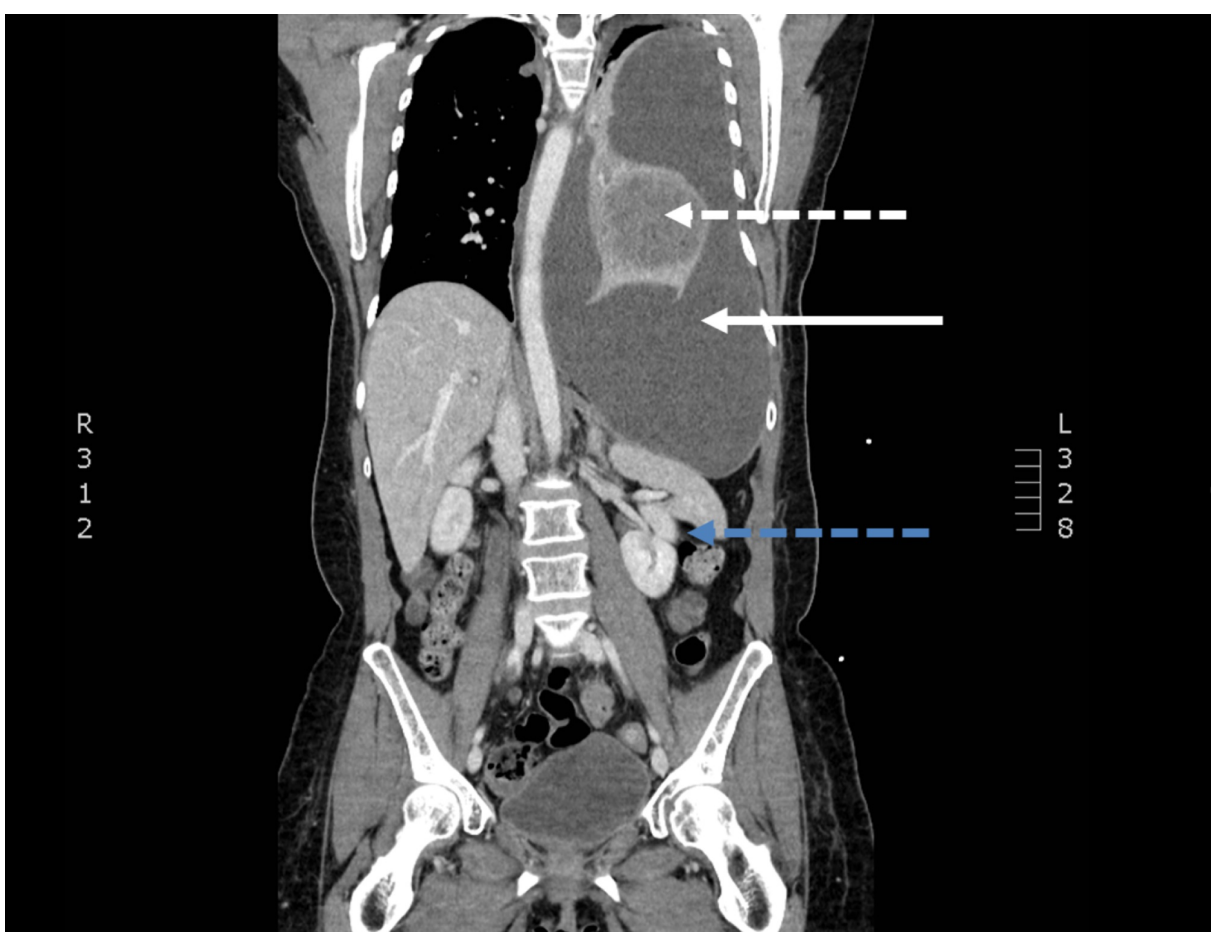

FIGURE 2: A coronal slice of contrasted computed tomography of the chest, abdomen, and pelvis demonstrating a complex mass (dashed white line) with associated large left-sided pleural effusion (solid white line) with mass effect on the left hemidiaphragm, left kidney, and spleen 
(dashed blue line)

\section{Discussion}

Leiomyosarcomas comprise $0.5 \%$ of lung neoplasms and can seed the lungs, remaining dormant for many years [3-4]. While the patient exhibited cardiorespiratory collapse secondary to mediastinal shift and left lung collapse, pulmonary metastases may also demonstrate left atrial extension, causing heart failure and pulmonary hypertension. These potential complications can create a clinically challenging scenario, necessitating the balance between low tidal volumes and inotropy [5]. While no large case series for pulmonary leiomyosarcomas exists, limited publications report a similar presentation of severe dyspnea and hemodynamic instability from massive pulmonary effusion [6-7].

In considering thoracentesis for diagnostic and symptomatic relief, no more than $2000 \mathrm{~mL}$ should be aspirated to avoid re-expansion pulmonary edema, a potentially lethal complication [8]. Although the exact pathogenesis of this phenomenon is unclear, rapid re-expansion, prolonged duration of lung collapse, decreased surfactant activity, and increased pulmonary vascular permeability secondary to micro-vessel injury appear to be contributing risk factors [9-11]. In the setting of malignant pleural effusion, especially in patients with metastatic leiomyosarcoma, judicious aspiration and possible manometry are critical.

If amenable to operative management, including patient preference and cancer grading and staging, surgical resection is the mainstay of treatment, with chemotherapy and radiation as adjuvant options [12]. However, if the tumor is unresectable, leiomyosarcomas have been shown to be sensitive to doxorubicin, ifosfamide, trabectedin, with a general response rate of $20 \%$; in these cases of large tumor burden and progressive disease, the median survival rate is estimated to be 12 months [13-14].

\section{Conclusions}

Pulmonary metastasis is a rare but immediately life-threatening complication of leiomyosarcoma. Pleural effusion and mass effect can cause both cardiorespiratory collapse while aggressive thoracentesis can further complicate resuscitation. Surgery with or without adjuvant therapy remains the mainstay of treatment in this aggressive cancer with poor survival rates.

\section{Additional Information \\ Disclosures}

Human subjects: Consent was obtained by all participants in this study. Conflicts of interest: In compliance with the ICMJE uniform disclosure form, all authors declare the following: Payment/services info: All authors have declared that no financial support was received from any organization for the submitted work. Financial relationships: All authors have declared that they have no financial relationships at present or within the previous three years with any organizations that might have an interest in the submitted work. Other relationships: All authors have declared that there are no other relationships or activities that could appear to have influenced the submitted work.

\section{Acknowledgements}

Disclaimer: The view(s) expressed herein are those of the author(s) and do not reflect the official policy or position of Brooke Army Medical Center, the U.S. Army Medical Department, the U.S. Army Office of the Surgeon General, the Department of the Army, the Department of the Air Force and Department of Defense or the U.S. Government.

\section{References}

1. Morrison BA: Soft tissue sarcomas of the extremities . Proc (Bayl Univ Med Cent). 2003, 16:285-290. 10.1080/08998280.2003.11927915

2. Gupta ML, Srivastava CP, Bageratta M, Katara R: Pulmonary leiomyosarcoma. Indian J Chest Dis Allied Sci. 2002, 44:129-131.

3. Livieratos S, Fatakhov E, Ammar A, Dillard T, Davis B: Metastasizing bronchopulmonary leiomyosarcoma. J Investig Med High Impact Case Rep. 2015, 10.1177/2324709615584000

4. Abramson S, Gilkeson RC, Goldstein JD, Woodard PK, Eisenberg R, Abramson N: Benign metastasizing leiomyoma. Am J Roentgenol. 2001, 176:1409-1413. 10.2214/ajr.176.6.1761409

5. Qu Y, Zheng Q, Ni C, Cui Z, Guo X: Metastatic leiomyosarcoma presenting as a lung mass with left atrial extension: case report and anesthetic management. Ther Clin Risk Manag. 2018, 14:141-147. 10.2147/TCRM.S153484

6. Al-Daraji WI, Salman WD, Nakhuda Y, Eyden B: Primary smooth muscle tumor of the pleura: a clinicopathological case report with ultrastructural observations and a review of the literature. Ultrastruct Pathol. 2005, 29:389-398. 10.1080/019131290945709

7. Rais G, Raissouni S, Mouzount H, et al.: Primary pleural leiomyosarcoma with rapid progression and fatal outcome: a case report. J Med Case Rep. 2012, 6:101. 10.1186/1752-1947-6-101

8. Wan YY, Zhai C-C, Lin XS, et al.: Safety and complications of medical thoracoscopy in the management of 


\section{Cureus}

pleural diseases. BMC Pulm Med. 2019, 19:125. 10.1186/s12890-019-0888-5

9. Kim YK, Kim H, Lee CC, et al.: New classification and clinical characteristics of reexpansion pulmonary edema after treatment of spontaneous pneumothorax. Am J Emerg Med. 2009, 27:961-967.

10.1016/j.ajem.2008.07.036

10. Kim JJ, Kim YH, Choi SY, Jeong SG, Moon SW: Contralateral reexpansion pulmonary edema with ipsilateral collapsed lung after pleural effusion drainage: a case report. J Cardiothorac Surg. 2015, 10:68. 10.1186/s13019-015-0272-3

11. Kwon JB, Choi SY, Kim CK, Park CB: Reexpansion pulmonary edema after treatment of simultaneous bilateral spontaneous tension pneumothorax. J Cardiothorac Surg. 2013, 8:62. 10.1186/1749-8090-8-62

12. Sinha AK, Khanna A, Talwar D, Dbaral C: Primary pleural leiomyosarcoma - a rare entity . Lung India. 2017, 34:104-105. 10.4103/0970-2113.197095

13. Demetri GD, Chawla SP, von Mehren M, et al.: Efficacy and safety of trabectedin in patients with advanced or metastatic liposarcoma or leiomyosarcoma after failure of prior anthracyclines and ifosfamide: results of a randomized phase II study of two different schedules. J Clin Oncol. 2009, 27:4188-4196.

10.1200/JCO.2008.21.0088

14. Bramwell V, Anderson D, Charette M: Doxorubicin-based chemotherapy for the palliative treatment of adult patients with locally advanced or metastatic soft tissue sarcoma. Cochrane Database Syst Rev. 2003, 3:14651858. 10.1002/14651858.CD003293 